See discussions, stats, and author profiles for this publication at: https://www.researchgate.net/publication/327021920

\title{
Spondyloarthropathy in vertebrae of the aquatic Cretaceous snake Lunaophis aquaticus, and its first recognition in modern snakes
}

Article in The Science of Nature · October 2018

DOI: 10.1007/s00114-018-1576-7

CITATIONS

READS

0

65

4 authors:

Adriana Albino

Universidad Nacional de Mar del Plata

79 PUBLICATIONS 1,025 CITATIONS

SEE PROFILE

Jorge Domingo Carrillo Briceño

University of Zurich

55 PUBLICATIONS 253 CITATIONS

SEE PROFILE

Some of the authors of this publication are also working on these related projects:

skeletal pathology View project

Project Fossil squamates of South America View project 
1 Spondyloarthropathy in vertebrae of the aquatic Cretaceous snake Lunaophis

2 aquaticus, and its first recognition in modern snakes

3 Adriana Marìa Albino ${ }^{1} \cdot$ Bruce Rothschild $^{2,3} \cdot$ Jorge D. Carrillo-Briceño $^{4} \cdot$ James M. $^{2}$

$4 \quad$ Neenan $^{5}$

$5{ }^{1}$ CONICET, Departamento de Biología, Universidad Nacional de Mar del Plata, Funes

6 3250, B7602AYJ Mar del Plata, Argentina, aalbino@mdp.edu.ar

$7 \quad 2$ Department of Medicine, Western Michigan University, Kalamazoo, MI 49008, United

8 States of America

$9 \quad{ }^{3}$ Carnegie Museum, Pittsburgh, Pennsylvania, United States of America

$10{ }^{4}$ Paläontologisches Institut und Museum, Universität Zürich, Zürich, Switzerland

$11{ }^{5}$ Oxford University Museum of Natural History, Oxford, United Kingdom

\section{Abstract}

14 Arthritis is documented for the first time in snakes. Ossification of the intervertebral 15 capsule and zygapophyseal joints resulting in segmental vertebral fusion was observed in

16 the aquatic Cretaceous snake Lunaophis aquaticus. Such pathologic alterations are

17 pathognomonic for the spondyloarthropathy form of inflammatory arthritis. The alterations

18 are easily distinguished from vertebral fractures because of the absence of collapse and

19 from osteomyelitis and neoplasia because of absence of destructive changes and reactive

20 new bone formation. A survey of 2144 snakes in recent collections, performed to identify

21 Holocene prevalence, revealed only two occurrences in extant snakes. The findings in Bitis

22 gabonica and Elaphe taeniura were indistinguishable from those noted in Lunaophis

23 aquaticus and identical to those previously recognized in modern varanids. The pathology

24 likely represents a form of reactive arthritis related to enteropathic infection. While the 
25 disease probably did not affect general locomotion, its vertebral column position may have 26 compromised mating.

27 Keywords Spondyloarthropathy $\bullet$ Mesozoic $・$ Marine snakes $\bullet$ South America $\bullet$ Venezuela 28

29 Acknowledgments This paper was partially supported by Consejo Nacional de

30 Investigaciones Científicas y Técnicas grant to A.M.A (CONICET-PIP 112-201501-

31 00065), Swiss National Science Foundation grant 31003A-149605 (awarded to Marcelo

32 Sánchez-Villagra, Zürich) and Leverhulme Trust Early Career Fellowship (ECF-2017-360,

33 awarded to J.M.N). Appreciation is expressed to David Dickey, David Kiziriain, Steve

34 Rogers, Kenneth A. Tighe and Loren Vonahme for hosting access to the collections they

35 curate, and to members of the Evolutionary Morphology and Palaeobiology group at the

36 Palaeontological Institute and Museum (University of Zurich, Switzerland) for generous

37 collaboration.

38 


\section{Introduction}

Lunaophis aquaticus is a representative of an early lineage of snakes that exploited tropical marine pelagic environments of Cretaceous northern South America (Albino et al. 2016). It is known by several precloacal vertebrae from sediments of the Cenomanian La Luna Formation in the Andes of Venezuela. A short portion of articulated vertebral column of this snake reveals an osseous pathology previously unreported in any snake.

Reported cases of snake postcranial osseous pathology have been limited to those of traumatic, infectious and neoplastic (tumor) origin (Isaza et al. 2000; Rothschild et al. 2012). The report suggesting Paget's disease was diagnosed on the basis of disorganized osseous architecture (Frye and Carney 1974). Although a viral cause (based on electron microscopically recognized structures suggested of measles or respiratory syncytial virus in humans) has been suggestive for Paget's disease (Altman and Singer 1980), the bone alterations in Frye and Carney (1974) have been reinterpreted as representing bacterial osteomyelitis (Rothschild and Martin 2006; Rothschild et al. 2012). The two are morphologically distinguishable on the basis of gross morphology, but not histology. In this study, we describe the occurrence of spondyloarthropathy in vertebrae of Lunaophis aquaticus. Spondyloarthropathy is a form of arthritis in which the margins of vertebrae are bridged through either the outer layers of intervertebral disks or joint capsules (Resnick 2006; Rothschild and Martin 2006). This pathology has been previously recognized in extant varanids and crocodylians (Rothschild 2008) and in the fossil record of mosasaurs (Rothschild and Everhart 2015), but not for either fossil or Recent snakes (Rothschild et al. 2012). We provide evidence supporting the diagnosis of this pathology in Lunaophis, which constitutes the first instances of this kind of arthritis in snakes (both from 
62 a phylogenetic and from a chronologic perspective). Additionally, we surveyed extant

63 snake collections to determine the occurrence and prevalence of the phenomenon.

64 Materials and methods

65 The pathologic fossil vertebrae investigated in this study are catalogued and stored at the 66 collection of the Museo de Ciencias Naturales de Caracas, Venezuela (MCNC). The

67 specimen was composed of the vertebral remains of a single individual, preserved in a

68 small block of black shale (MCNC-1827). All vertebrae are consistent in size,

69 corresponding to a 1.5 meters long snake. The remains include four isolated preclocal

70 vertebrae (MCNC-1827-A, MCNC-1827-B, MCNC-1827-C, MCNC-1827-D), an isolated

71 anterior vertebra (MCNC-1827-E), five mid- or posterior precloacal vertebrae (MCNC-

72 1827-F), and a poorly preserved vertebral fragment (MCNC-1827-G). The pathologic

73 vertebrae correspond to the segment MCNC-1827-F.

74 Snakes in the collections of the American Museum of Natural History (AMNH),

75 Carnegie Museum (CM), National Museum of Natural History (NMNH) and Texas

76 Memorial Museum (TMM) were examined by epi-illumination microscopy (Dino-lite,

77 AM7915MZT, Dunwell Tech, Inc, 19803 Hamilton Ave \#200, Torance CA 90502) for

78 vertebral bridging and fusion.

79 Spondyloarthropathy was recognized on the basis of intervertebral margin ossification

80 producing bridging/fusion of otherwise intact vertebrae (Resnick 2002; Rothschild and

81 Martin 2006), in the absence of vertebral compression characteristic of fractures and the

82 destructive bone changes with draining fibriscesses characteristic of osteomyelitis and mass

83 effect of neoplasia (Resnick 2002; Rothschild and Martin 2006; Rothschild et al. 2012).

84 Anterior longitudinal ligament ossification is a diagnostic characteristic of a phenomenon

85 referred to as diffuse idiopathic hyperostosis (DISH), when capsule fusion is not present 
86 (Resnick 2002; Rothschild and Martin 2006). Its presence, however, does not rule out

87 spondyloarthropathy, which is also associated with such ligamentous ossification (Resnick

88 2002; Rothschild and Martin 2006). The presence of intact intervertebral spaces allowed

89 spondyloarthropathy to be distinguished from congenital block vertebrae (Burnham et al.

90 2013; Resnick 2002; Rothschild and Martin 2006; Rothschild et al. 2012).

91 Geological setting

92 The vertebrae of Lunaophis aquaticus were found exposed in a quarry of the Cementos

93 Andinos company, $10 \mathrm{~km}$ northeast of Monay city (9³6.57' 06"N, 70²4'14"W), Municipo

94 Candelaria, Trujillo State, Venezuela (Albino et al. 2017). The fossils come from strata

95

96

97

98

99

100

101

102

103

104

105

106

107

108

109 corresponding to the La Aguada Member of the La Luna Formation (Albino et al. 2017;

Guinot and Carrillo-Briceño 2018). A Cenomanian age for the La Aguada Member was

determined by planktonic foraminifera and ammonites (Renz 1959). Associated fauna from

the same strata as Lunaophis indicate a marine environment, and include bivalves, sharks

and bony fishes (Albino et al. 2016; Guinot and Carrillo-Briceño 2018).

\section{Results}

\section{Paleoecology of Lunaophis aquaticus}

Examination of the vertebral morphology reveals that Lunaophis aquaticus resembles simoliophiids (Albino et al. 2016), the earliest sea-invaders in the evolution of snakes

(Hsiang et al. 2015). Lunaophis represents the first aquatic snake from the Cenomanian found outside of the African and European Tethyan and Boreal Zones, which is where the simoliophiids have been previously documented (Albino et al. 2016).

All simoliophiids display pachyostosis in which the centrum and neural arch are swollen in all dimensions, increasing the mass of the vertebrae (Lee and Caldwell 1998;

Houssaye 2010; Rage et al. 2016). Pachyostosis is a non-pathological condition in these 
110

111

112

113

114

115

116

117

118

119

120

121

122

123

124

125

126

127

128

129

130

131

132

133

vertebrates in which the bones experience a thickening, generally caused by extra layers of lamellar bone (Houssaye 2009). It occurs in both terrestrial and, especially, aquatic or semiaquatic vertebrates. The pachyostosis in Lunaophis is less evident than in simoliophiids, and is concentrated on the prezygapophyseal bodies and on the posterior part of the neural arch, above the postzygapophyses (Fig. 1a).

In addition, the vertebrae of Lunaophis are characterized by the ventral position of the paradiapophyses, which are closely spaced, project ventrally from the centrum, and bear ventrally oriented surfaces (Fig. 1a). This morphology contrasts with the morphology of terrestrial, arboreal and fossorial snakes, in which the paradiapophyses are well-separated each other, not projected from the centrum and have lateroventrally-oriented surfaces determining a lateralized articulation of the ribs with the vertebra (Fig. 1b). The hypothetical ribs of Lunaophis would have been articulated with the paradiapophyses ventrally to the vertebral centra (Fig. 1c). Thus, the body of this snake was strongly compressed laterally, giving it an eel-like appearance as an adaptation for swimming. Aquatic habits are supported by the size of the snake, presence of pachyostosis, and depositional conditions of the La Aguada Member of the La Luna Formation. Spondyloarthropathy in vertebrae of Lunaophis and extant snakes

Spondyloarthropathy was recognized in MCNC-1827-F (Fig. 2a, b) on the basis of osseous fusion of the capsule surrounding intervertebral spaces (Resnick 2002; Rothschild and Martin 2006), while normal vertebral shape and configuration were retained. Examination of 2144 modern snakes revealed only one additional affected snake, the viperid Bitis gabonica CM145474S (Fig. 2c, d). Fusion of posterior (facet) joints is also present in Lunaophis aquaticus MCNC-1827-F (Fig. 2c). This is distinguished from congenital vertebral pathology which represents segmentation defects, predominantly failure of 
134 segmentation or failure of development of one of the segments (e.g., hemivertebra or block

135 vertebrae) that normally combine to form a normal vertebra (Burnham et al. 2013).

136 Fusion through the outer layers of the capsule joining vertebral centra (Fig. 2) is

137 pathognomonic (definitive) for spondyloarthropathy (Resnick 2002; Rothschild and Martin

138 2006; Rothschild et al. 2012). It is accompanied by ligamentous ossification. Vertebral

139 body shape and configuration appear otherwise unaltered.

140 Discussion

141 These observations represent the first recognition of the inflammatory arthritis condition,

142 spondyloarthropathy, in fossil snakes, and establish the geological depth of this disease.

143 This condition is apparently rare in snakes, as there is only one recent case, other than that

144 discovered in Bitis gabonica in the current study, noted to date. Marcus (1981) initially

145 reported an anomaly affecting the extant snake Elaphe taeniura as osteoperiostitis, but

146 Rothschild et al. (2012) suggest it would correspond to spondyloarthropathy, which is

147 confirmed here.

148 Differential diagnosis: Lack of vertebral disruption and draining sinuses rules out

149 osteomyelitis (Jacobson 2007; Resnick 2002; Rothschild and Martin 2006). Maintainance

150 of vertebral body shape and intervertebral spaces is incompatible with fracture or segmental

151 defect evidencing congenital origin of the pathology. Presence of capsular calcification

152 dismisses DISH as a diagnostic consideration. The associated ligamentous ossification in

153 Lunaophis aquaticus MCNC-1827-F represents the enthesial reaction commonly found in

154 individuals with spondyloarthropathy.

155 Spondyloarthropathy is a classification consisting of several diseases (Resnick 2002;

156 Rothschild and Martin 2006): 1) A primary arthritis (ankylosing spondylitis). 2) A

157 dermatologically-related disorder, psoriatic arthritis. 3) Arthritis associated with 
158 inflammatory bowel diseases, ulcerative colitis and Crohn's disease. 4) A reactive arthritis

159 (previously referred to as Reiter's syndrome). 5) An undifferentiated form, not assignable

160 to the first four categories. Ankylosing spondylitis generally starts in what would be the

161 pelvic region and results in vertebral fusion proceeding uniformly in a cephalad (cranial)

162 direction (Resnick 2002; Rothschild and Martin 2006). If the precloacal fused Lunaophis

163 aquaticus vertebrae represent the most posterior portion of that segment, early ankylosing

164 spondylitis or inflammatory bowel disease could be considered as the specific variety of

165 spondyloarthropathy. Reactive arthritis, psoriatic arthritis and the undifferentiated form of

166 spondyloarthropathy are not so limited in vertebral column distribution (Resnick 2002;

167 Rothschild and Martin 2006). While psoriasis is characterized by erythematous skin

168 reaction with scale shedding, this is quite different from snake dysecdysis, with residual

169 tissue from normal skin shedding, and the hyperkeratosis that can complicate vitamin A

170 deficiency (Marcus 1981). Skin disease in the form of psoriasis has not been recognized in

171 snakes. However, reactive arthritis is worthy of consideration. The term "reactive" refers to

172 the bone alterations that can take place subsequent to what is generally referred to as food

173 poisoning by such organisms as enteropathic (intestinal wall invading) Escherichia coli,

174 Salmonella, Shigella, Campylobacter and Yersinia bacteria (Rothschild and Martin 2006).

175 The originating infection has generally resolved, but is followed by an immunologic

176 reaction producing the pathology. Such intestinal infections have been reported in snakes

177 (Jacobson 2007) and gastritis has been related to parasitic infection (Brownstein et al.

178 1977), which can cause inflammatory bowel disease in humans (Nime et al. 1976).

179 Reactive arthritis and ankylosing spondylitis are the most likely varieties of

180 spondyloarthropathy reponsible for the vertebral alterations in Lunaophis aquaticus

181 MCNC-1827-F. 
182

183

184

185 186

It is unclear that involvement of such a limited portion of the vertebral column would have impaired movement or ability to capture prey. It may, however, have impeded the physical act of mating. This form of arthritis may be quite painful and thus could have impacted the snake's quality of life.

\section{References}

Albino AM, Carrillo-Briceño JD, Neenan JM (2016) An enigmatic aquatic snake from the Cenomanian of Northern South America. PeerJ 4:e2027. doi 10.7717/peerj.2027

Altman RD, Singer F (1980) Proceeding of the Kroc Foundation conference on Paget's disease of bone. Arthritis Rheum. 23:1073-1234.

Brownstein DG, Stgrandbert JD, Montali RJ, Bush M, Foretner J (1977) Cryptosporidium in snakes with hypertrophic gastritis. Vet. Pathol. 14:606-617.

Burnham DA, Rothschild BM, Babiarz J, Martin LD (2013) Hemivertebrae as pathology and as a window to behavior in the fossil record. Pal Arch's J. Vert. Palaeontol. 10:16.

Frye Fl, Carney J (1974) Osteitis deformans (Paget's disease) in a boa constrictor. Vet. Med. Small Anim. Clin. 69:186-188.

Guinot G, Carrillo-Briceño J (2018) Lamniform sharks from the Cenomanian (Upper Cretaceous) of Venezuela. Cret. res. 82:1-20.

Houssaye A (2009) "Pachyostosis" in aquatic amniotes: a review. Integrative Zool. $4(4): 325-340$.

Houssaye A (2010) Rediscovery and description of the second specimen of the hindlimbed snake Pachyophis woodwardi Nopcsa 1923 (Squamata, Ophidia) from the Cenomanian of Bosnia Herzegovina. J. Vert. Paleontol. 30:276-279. doi $10.1080 / 02724630903416043$ 
Hsiang AY, Field DJ, Webster TH, Behlke ADB, Davis MB, Racicot RA, Gauthier JA (2015) The origin of snakes: revealing the ecology, behavior, and evolutionary history of early snakes using genomics, phenomics, and the fossil record. BMC Evol. Biol. 15:87. doi 10.1186/s12862-015-0358-5

Isaza R, Garner M, Jacobson E (2000) Proliferative osteoarthritis and osteoarthrosis in 15 snakes. J. Zoo Wildl. Med. 31:20-27.

Jacobson ER (2007) Infectious Diseases and Pathology of Reptiles: Color Atlas and Text. Boca Raton: CRC Press.

Lee MSY, Caldwell MW (1998) Anatomy and relationships of Pachyrhachis problematicus, a primitive snake with hindlimbs. Philos. Trans. R. Soc. Lond. B 353:1521-1552. doi 10.1098/rstb.1998.0308.

Marcus LC (1981) Veterinary Biology and Medicine of Captive Amphibians and Reptiles. Lea \& Febiger, Philadelphia.

Nime FA, Burek JD, Page DL, Holscher MA, Yaardley JH (1976) Acute enterocolitis in a human being infected with the protozoan Cryptosporidium. Gastroenterol. 70:592-598.

Rage JC, Vullo R, Néraudeau D (2016) The mid-Cretaceous snake Simoliophis rochebrunei (Sauvage, 1880) (Squamata: Ophidia) from its type area (Charentes, southwestern France): redescription, distribution, and palaeoecology. Cret. Res. 58:234-253. doi 10.1016/j.cretres.2015.10.010.

Renz O (1959) Estratigrafía del Cretáceo en Venezuela occidental. Bol. Geol. 5:3-48.

Resnick D (2002) Diagnosis of Bone and Joint Disorders. Saunders, Philadelphia.

Rothschild BM (2008) Scientifically rigorous reptile and amphibian osseous pathology: Lessons for forensic herpetology from comparative and paleo-pathology. Appl. Herpetol. 10:39-116. 
230 Rothschild BM, Everhart MJ (2015) Co-ossification of vertebrae in mosasaurs (Squamata, 231 Mosasauridae); Evidence of habitat interactions and susceptibility to bone disease.

232 Trans. Kans. Acad. Sci. 118:265-275.

233 Rothschild BM, Martin LD (2006) Skeletal Impact of Disease. Albuquerque: New Mexico $234 \quad$ Museum of Natural History Press.

235 Rothschild BM, Schultze HP, Pellegrini R (2012) Herpetological Osteopathology:

236 Annotated Bibliography of Amphibians and Reptiles. Springer, New York.

237

238 


\section{$239 \quad$ Figure captions}

240 Figure 1. a Pachyostosis (pch) in isolated precloacal vertebra of Lunaophis aquaticus

241 MCNC-1827-A (anterior, lateral and dorsal views). b Trunk vertebrae and articulated

242 ribs of terrestrial Boa constrictor occidentalis. c Trunk vertebrae and hypothetical

243 articulated ribs of aquatic Lunaophis aquaticus.

244 Figure 2. a Ventral view of Lunaophis aquaticus MCNC-1827-F vertebrae, fusion of

245 vertebrae through intervertebral capsule. b Left lateral view of Lunaophis aquaticus

246 MCNC-1827-F vertebrae, continuous fusion of longitudinal ligament. c Ventral view

247 of Bitis gabonica CM145474S vertebrae. d Lateroventral view of Bitis gabonica

248 CM145474S vertebrae, fusion of both zygapophyseal joints and intervertebral capsule;

249 pd, paradiapophysis; pr, prezygapophysis; pz, postzygapophysis; vc, vertebral centrum; 


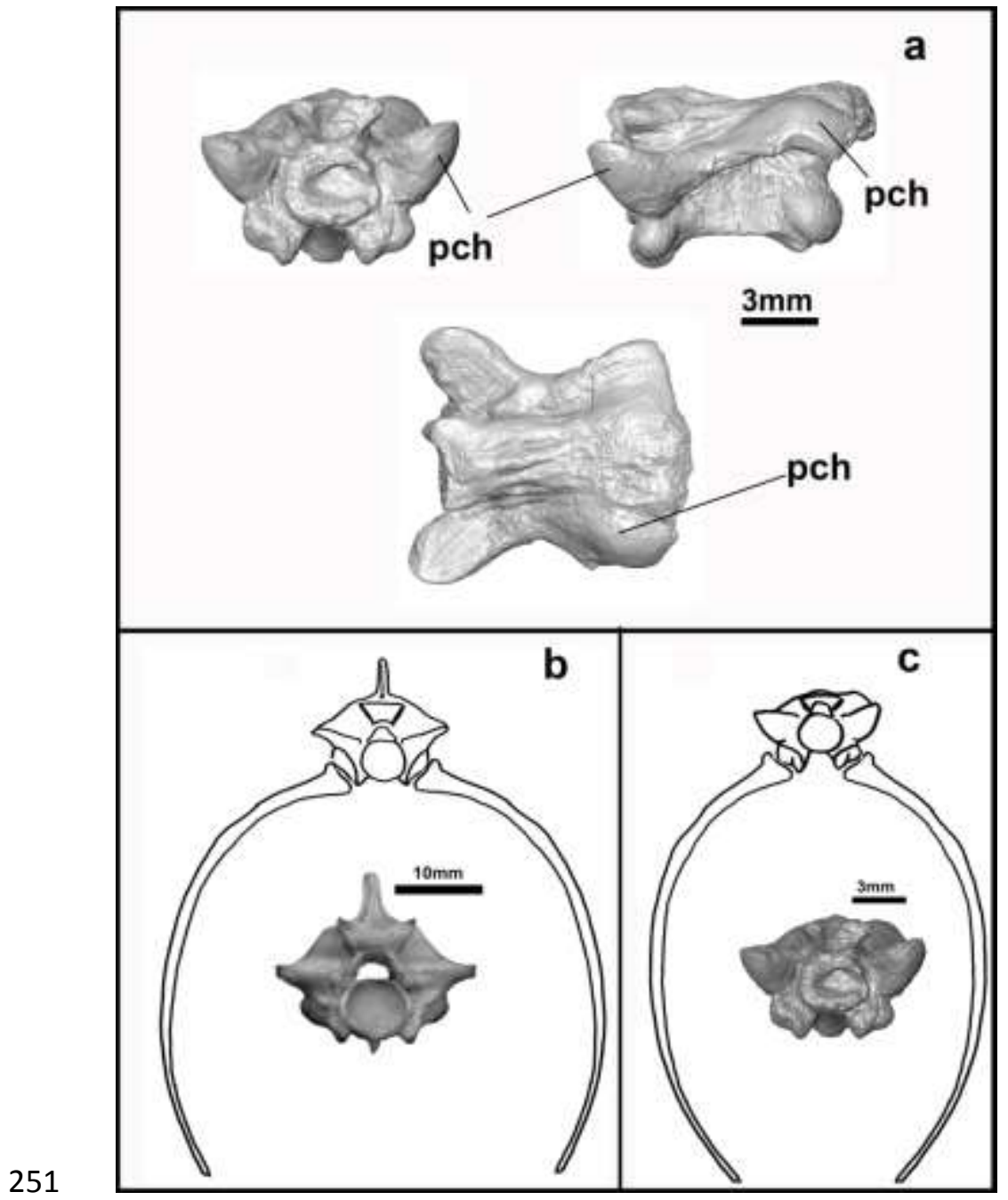

252 


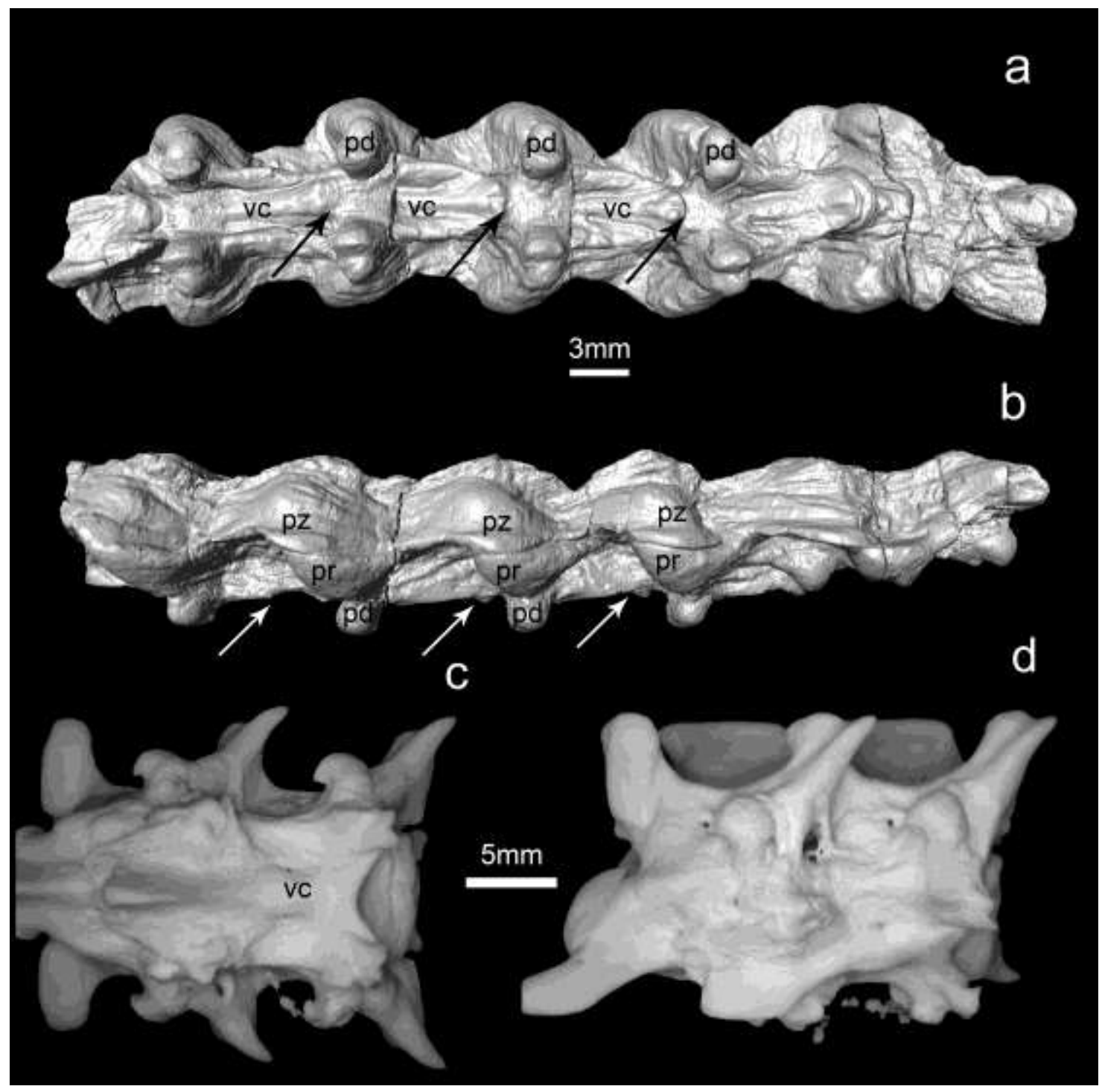

255

256

257 